\title{
Study of the Properties of Absorption and Transmission of Borax glass and Windows Glass Coated by Vanadium Oxides by using Helium Neon $(\mathrm{He}-\mathrm{Ne})$ Laser
}

\author{
Safa Osman Zacharia Adam ${ }^{1}$, Mahmoud Hamid Mahmoud Hilo² \\ ${ }^{1}$ Sudan Atomic Energy Commission, Radiation Safety Institute \\ ${ }^{2}$ Sudan University of Science and Technology
}

\begin{abstract}
This paper studied the glass optical properties for two types of glass, the unique characteristics which classify each type; also it shows the ability of improving the physical optical properties, such as transmission and absorption of light laser as example throughout the windows glass coated by vanadium oxides, and Borax glass. It found that, the glass of windows coated by vanadium oxides, and Borax glass which fabricated within this research, both of them, give better results in improving some physical properties, compared to the other types of glass, although that the inversely proportional relation between the glass thickness and light transmission does not change.
\end{abstract}

Keywords: Borax glass, windows glass, vanadium oxides, thickness

\section{Introduction}

Glass is composed of combination of different materials oxides. For example silicon oxides mixed with various metal oxides. There are many types and uses of glasses like ceramic used in buildings, flat glass, sheet glass, glass pane or plate glass used in (windows or windshield, optical fiber) and all previous types are have properties such as durability, hardness, strength, brittleness, thermal resistance, density, refractive index and transmitter of visible light [1].

There last studies; nowadays, many new materials have been investigated for the purpose of their application in transparent electronics devices. Among them, oxides based on Ti , V (Transparent Oxide Semiconductor). Vanadium, as an element, creates many compounds with oxygen, resulting in materials with different structural, optical and chemical properties. Differences between various vanadium oxides depend on their structure which determines their specific properties [2-5].

Several oxides of vanadium transition from a semiconductor or insulating state to a metal phase at a critical temperature. Vanadium dioxide undergoes this transition near $68^{\circ} \mathrm{C}$, while $\mathrm{V}_{2} \mathrm{O}_{5}$ undergoes a similar phase transition near $257^{\circ} \mathrm{C}$. During the transition a change in oxide crystal structure is accompanied by large changes in electrical and optical behavior [6].

This paper intended to improve the ordinary glass used by vanadium pent oxide, addition of different metals oxides.

The problems which discussed within this paper is that, the glass transmission or absorption of light can only be controlled by coating, not depending on the glass optical properties, on light characteristics.
The goal of this paper is test of the physical optical properties (Transmission, Absorption) for Borax glass and windows glass coated by vanadium pent oxide. Found a kind of glass with a property of passing light and rejecting infrared is a significant goal of research. So research was training to add a new step in this way.

Improve the ordinary glass by different metals addition.

\section{Materials and Methods}

This section considers very important part of materials and methodology (work applied principle) of devices and ways of measures of properties and optical physical characteristics.

\section{Devices and Materials used}

Glass samples are composed of materials mentioned here, (silica oxide $\left(\mathrm{SiO}_{2}\right)$, sodium carbonate $\left(\mathrm{Na}_{2} \mathrm{CO}_{3}\right)$, calcium carbonate $\left(\mathrm{CaCO}_{3}\right)$, magnesium oxide $(\mathrm{Mg} \mathrm{O})$, aluminum oxide $\left(\mathrm{Al}_{2} \mathrm{O}_{3}\right)$, ), $\left(\mathrm{Li}_{2} \mathrm{CO}_{3}\right)$ lithium carbonate , vanadium pent oxide $\left(\mathrm{V}_{2} \mathrm{O}_{5}\right)$. An Oven with a maximum temperature of $1200{ }^{\circ} \mathrm{C}$. this give sensitive Balance to measure mass. Crucible from ceramic, bears high temperature and do not react with the, cup, optical devices (source of laser), sample of windows glass (slights from ordinary windows glass).

The sample of soda lime glass is composition of $20 \% \mathrm{Na}_{2}$ $\mathrm{CO}_{3}{ }_{-} 70 \% \mathrm{SiO}_{2}-7 \% \mathrm{Ca} \mathrm{CO}_{3}$ - $2 \% \mathrm{Mg} \mathrm{O} \_0.6 \% \mathrm{AL}_{2} \mathrm{O}_{3}$ $0.4 \% \mathrm{Li}_{2} \mathrm{CO}_{3}$.

The sample of Borax glass is composition of $50 \%$ sand, $40.4 \%$ feldspar borax, $1.33 \%$ whiting and $7.37 \%$ Microcline.

Molecular weights of components (in g mol-1) $\left(\mathrm{Na}_{2} \mathrm{O} 2 \mathrm{~B}_{2} \mathrm{O}_{3}\right.$ $10 \mathrm{H}_{2} \mathrm{O}$ ) weight Feldspar borax 40.4grams 


\section{International Journal of Science and Research (IJSR) \\ ISSN (Online): 2319-7064 \\ Index Copernicus Value (2013): 6.14 | Impact Factor (2014): 5.611}

$\left(\mathrm{K}_{2} \mathrm{O} \quad \mathrm{AL}_{2} \mathrm{O}_{3} \quad 6 \mathrm{SiO}_{2}\right)$ weight of Microcline 7.37 grams,(Ca $\left.\mathrm{CO}_{3}\right)$ weight calcium carbonate 1.33 grams, $\left(\mathrm{SiO}_{2}\right)$ weight of sand 50.90 grams.

\section{Methodology}

Experimental work is to have been done in two different steps:

One step of manufacture glass (Preparation of samples)

Steps used to manufacture glass.

Batching

Number different compounds in addition to pure oxides, can be used to form a glass melt .These include of raw materials given above in table.

\section{Mixing and melting}

Mixing these are materials to provide a homogeneous.

Then put a mixture each sample inside crucibles melting for sample Soda lime glass and sample borosilicate glass.

Put Samples inside the oven at $170^{\circ} \mathrm{C}$ temperature, elementary of degree heat. Temperatures were taken every 30 minutes until it was melting all the materials and homogenized with each other at $1080^{\circ} \mathrm{C}$

For soda lime glass

$\mathrm{Na}_{2} \mathrm{CO}_{3}+\mathrm{SiO}_{2} \rightarrow \mathrm{O} \mathrm{Na} 2 . \mathrm{SiO}_{2}+\mathrm{CO}_{2}$ (g)

$\mathrm{CaCO}_{3}+\mathrm{SiO}_{2} \rightarrow \mathrm{CaO} . \mathrm{SiO}_{2}+\mathrm{CO}_{2}(\mathrm{~g})$

$\mathrm{Li}_{2} \mathrm{CO}_{3}+\mathrm{SiO}_{2} \rightarrow \mathrm{Li}_{2} \mathrm{O} . \mathrm{SiO}_{2}+\mathrm{CO}_{2}$ (g)

$\mathrm{AL}_{2} \mathrm{O}_{3}+\mathrm{SiO}_{2} \rightarrow \mathrm{AL}_{2} \mathrm{O}_{3} \cdot \mathrm{SiO}_{2}$

$\mathrm{MgO}+\mathrm{SiO}_{2} \rightarrow \mathrm{M} \mathrm{g} \mathrm{O} . \mathrm{SiO}_{2}$

Formation of new eutectic mixture $\mathrm{Na}_{2} \cdot 2 \mathrm{SiO}_{2}$ at $800^{\circ} \mathrm{C}$.

\section{Refining}

After process the melting. The initial refining and molding of molten (borosilicate) on iron a plate coating for soap and flour to prevent the contiguity; but cannot molding of soda lime glass because high temperature needed between (1550 - 1600) ${ }^{\circ} \mathrm{C}$, the found maximum temperature for oven $1200^{\circ} \mathrm{C}$.

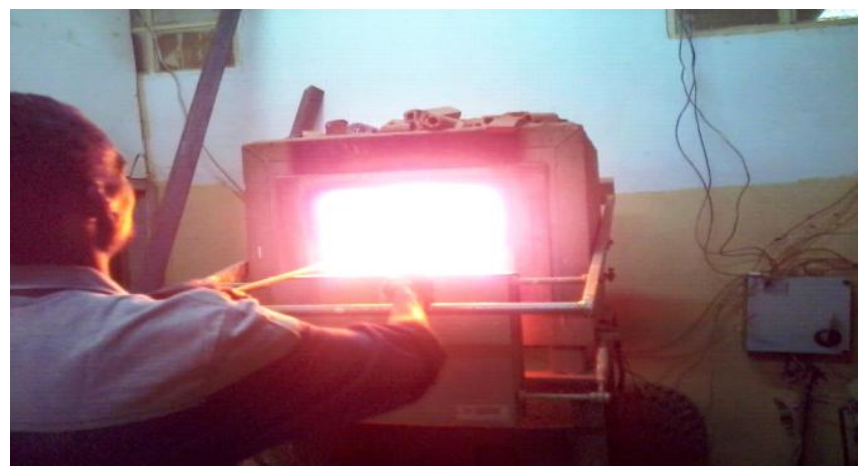

Image (1): Melting

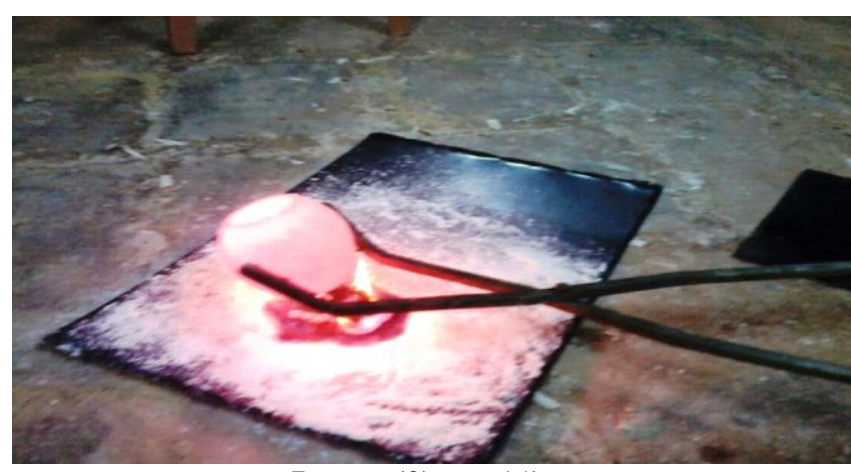

Image (2): Molding

Conditioning (cooling)

Reduced temperature and start time of sample fast cooling and then the glass.

\section{Forming}

Can be glass is form of (plate or sheet) but cannot soda lime (glass windows) form therefore replace samples of soda lime glass (glass windows).

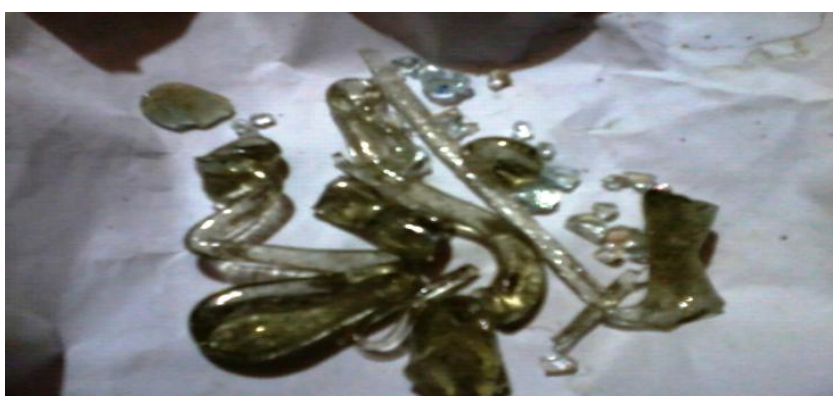

Image (3): Borax glass

glass windows in the markets proportion to the difficulty of molding and forming a slice of glass that was manufactured and also the lack of an oven at high temperatures until it becomes molten more liquid and less viscous so it has to study the samples ready replaced.

Glass samples are ready to study.

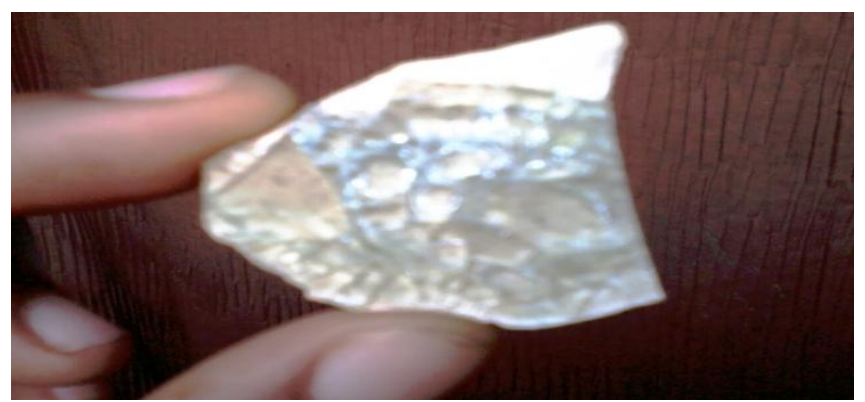

Image (4): Soda lime glass (windows glass)

The second step study of the physical properties optical of to samples:

- Samples were thickness

- Reached a circuit electrical to measure both voltage and current to borosilicate glass and glass windows; those are not conductivity because both voltage and current are not reading.

- Samples of the Light Source offered. 


\section{International Journal of Science and Research (IJSR) \\ ISSN (Online): 2319-7064 \\ Index Copernicus Value (2013): 6.14 | Impact Factor (2014): 5.611}

- study both of transmission and absorption of incidence light radiation on crystals (samples) by ordinary light and laser helium neon ( $\mathrm{He}$ - Ne) of wavelength $632.8 \mathrm{~nm}$ Adjust each of the laser and detector, those are contacted of electrical source,

- (I) took the normal optical intensity light $\left(\mathrm{I}_{0}\right)$ The samples are placed between the detector and source light (laser helium neon or ordinary light) where the sample mode (slice) every time the recorded intensity transmitted light (I) of each sample by Detector Repeated the experiment for various samples of various thickness a glass.

- Results recorded in the chapter four.

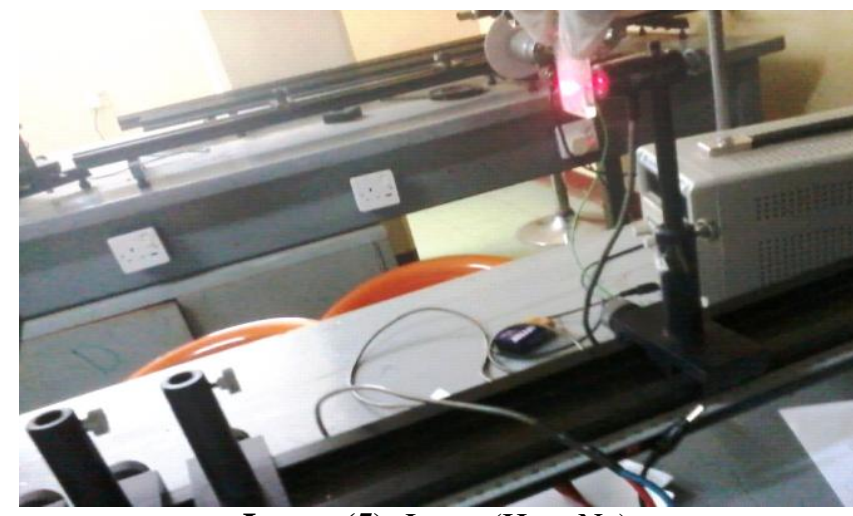

Image (5): Laser ( $\mathrm{He}-\mathrm{Ne})$

\section{Results and Discussion}

Results found below each of the absorption coefficient and transmittance light for the glass, when used source light (ordinary light and laser Helium Neon) accordingly laws of the following. Can be finding absorption coefficient by used this equation.

$\mathrm{I}=\mathrm{I}_{0} \exp (-\alpha \mathrm{x})$

$\left(\mathrm{I} / \mathrm{I}_{0}\right)=\exp (-\alpha \mathrm{x})$

$\left.\alpha=-\left(\ln \left(\mathrm{I} / \mathrm{I}_{0}\right)\right) / \mathrm{x}\right)$

$\mathrm{I}=$ incidence intensity radiation

$\mathrm{I}_{0}=$ intensity transmittance radiation

$(\alpha)=$ absorption coefficient

$\mathrm{x}=$ thickness

$\varepsilon=\mathrm{I} / \mathrm{I}_{0}$

$(\varepsilon)=$ permeability

Table 1: Calculation of the permeability (transmission) and absorption

Coefficient used by above equations $\mathrm{I}=\boldsymbol{\varepsilon}$ and $\mathrm{I}_{0}=246$

\begin{tabular}{|c|c|c|c|}
\hline Sample & $\begin{array}{c}\text { Thickness } \\
(\mathrm{mm})\end{array}$ & $\begin{array}{c}\text { Permeability } \\
\left(\begin{array}{c}\text { transmission) } \\
(\varepsilon) \text { or }(\mathrm{I})=\mathrm{I}_{0}\end{array}\right.\end{array}$ & $\begin{array}{c}\text { Absorption } \\
\text { coefficient }(\alpha) \\
=-\left(\mathrm{Ln}\left(\mathrm{I} / \mathrm{I}_{0}\right)\right) / \mathrm{x}\end{array}$ \\
\hline Sodium borosilicate & 1.01 & 0.65 & 5.877 \\
& 1.92 & 0.512 & 3.216 \\
& 2.318 & 0.545 & 2.637 \\
\hline Soda lime (windows & 2.512 & 0.8699 & 2.25 \\
glass) & & & \\
\hline Coating glass by & 2.512 & 0.126 & 3.016 \\
vanadium pent oxide & & 0.309 & 2.66 \\
& & 0.244 & 2.75 \\
\hline
\end{tabular}

\section{Discussion}

In this paper, the use of vanadium pent oxide coating at glass, besides fabricating of a Borax glass is extended to find a new property of glass within optical and physical characteristics testing. It found that the coating gives a better improving in glass properties especially in the way of passing of the laser light and rejecting the infrared the inversely proportional relation between, glass thickness and light transmission does not change.

The comparison between ordinary windows glass and coated windows glass by vanadium pent oxide from whereat (absorption coefficient and light transmission), absorption coefficient for windows glass is los than that found by coated glass because of the high transmission of light, at a high values of glass thickness.

\section{Conclusion}

From the above results after conducting the experiment and calculations found the absorption coefficient and permittivity of light or transmission light proportionate inversely with thickness of sample.

\section{Recommendations}

Available of laboratories scientific by all devices and apparatuses and increased of studies about the glass and development make of the glass. Usefulness from raw materials of local the found in the Sudan in manufacture glass, because the Sudan have many fortune of raw materials which the input in the manufacturing for example sand (silica).

\section{References}

[1] Forensic Science Prof. Nehru, CC 30.07 spring 2007.

[2] MANNING, T. D., PARKIN I. P. Vanadium (IV) oxide thin films on glass and silicon from the atmospheric pressure chemical vapor deposition reaction of VOCL3 and water. Polyhedron, vol. 23, p. 3087-3095, (2004).

[3] WANG, X. J., LI, H. D., FEI, Y. J., WANG, X., XIONG, Y. Y., NIE, Y. X., FENG, K. A. XRD and Raman study of vanadium oxide thin films deposited on fused silica substrates by RF magnetron sputtering. Applied Surface Science, vol. 177, p. 8-14, (2001).

[4] LEE, S. H., CHEONG, H. M., SEONG, M. J., LIU, P., TRACY, C. E., MASCARENHAS, A., PITTS, J. R., DEB, S. K. Raman spectroscopic studies of amorphous vanadium oxide thin films. Solid State Ionics, 2003, vol. 165, p. 111-116.

[5] S. Chaiyapinunt, B. Phueakphongsuriya, K. Mongkornsaksit, and N. Khomporn, "Performance rating of glass windows transmits and glass windows with films in aspect of thermal comfort and heat transmission," Energy and Buildings, vol. 37, pp. 725-738, 2005.

[6] Optical Society of America, (1991). 